\title{
A Numerical Model for Nozzle Flow Application under LOX/CH4 Hot Flow Conditions
}

\author{
Dirk Schneider* and Chloé Génin ${ }^{\dagger}$ \\ German Aerospace Center (DLR), Lampoldshausen, D-74239, Germany \\ Sebastian Karl ${ }^{\ddagger}$ and Volker Hannemann ${ }^{\ddagger}$ \\ German Aerospace Center (DLR), Göttingen, D-37073, Germany
}

\begin{abstract}
A numerical study was conducted at the German Aerospace Center in Lampoldshausen, to investigate the impact of various chemical models on reactive nozzle flow. Therefore, a chemical reaction mechanism for oxygen/methane combustion was implemented into DLR's flow solver TAU. Ignition delay simulations were conducted to demonstrate the validity of the implementation. The implemented baseline chemistry model was applied for generic nozzle flow simulations and the results were compared to frozen nozzle flow and nozzle flow in chemical equilibrium, in order to investigate the impact of the finiterate approach. The baseline reaction mechanism was reduced to a basic configuration and applied to the generic nozzle flow. A good agreement with the baseline model was observed. Both approaches were applied for dual-bell nozzle flow simulations. Validation data for the simulations were obtained during a hot flow test campaign. The experiments yielded a clear impact of the combustion chamber mixture ratio on the dual-bell transition nozzle pressure ratio. RANS simulations of the dual-bell nozzle flow were conducted and almost no deviation between baseline and reduced chemical approach was observed. A reduction of $93 \%$ of the computational cost was reached with the reduced model. The dual-bell transition behavior at different values of combustion chamber mixture ratio was investigated, applying RANS simulations with reduced chemistry model. The impact of the mixture ratio on the transition NPR was clearly reproduced by the numerical approach. A good agreement with the experimentally obtained transition NPR values was reached.
\end{abstract}

\section{Nomenclature}

$A$

$A_{r}$

$E_{\text {ac }}$

$k$

$p$

$R$

$T$

$X$

$x, y, z$

$y^{+}$

Subscripts

0

a

$\mathrm{b}$
Area

Arrhenius factor

Activation energy

Reaction rate

Pressure

Radius

Temperature

Mole fraction

Cartesian coordinates

Dimensionless wall spacing

Total condition

Ambient

Base nozzle

*PhD Candidate, Institute of Space Propulsion, Langer Grund, Lampoldshausen. dirk.schneider@dlr.de. Member AIAA.

${ }^{\dagger}$ Research Scientist, Institute of Space Propulsion, Langer Grund, Lampoldshausen. Member AIAA.

${ }^{\ddagger}$ Research Scientist, Institute of Aerodynamics and Flow Technology, Bunsenstrasse 10, Göttingen. 


$\begin{array}{ll}\text { cc } & \text { Combustion chamber } \\ \text { d } & \text { Design } \\ \text { e } & \text { Nozzle extension } \\ \text { th } & \text { Throat } \\ \text { t } & \text { Total }\end{array}$

\section{Conventions}

Equ

Froz

$\mathrm{Ma}$

Non - equ

AUSM

LOX

MOC

MUSCL

$\mathrm{NOx}$

NPR

$\mathrm{PP}$

$\mathrm{ROF}$

TIC

Symbols

$\alpha_{\mathrm{i}}$

$\beta$

$\epsilon$

$\epsilon_{\mathrm{c}}$

$\mathcal{R}$

$\Phi$

$\tau_{\text {ign }}$
Equilibrium flow

Frozen flow

Mach number

Non-equilibrium flow

Advection Upstream Splitting Method

Liquid oxygen

Method of Characteristics

Monotonic Upstream-Centered Scheme for Conservation Laws

Nitrogen Oxides

Nozzle Pressure Ratio

Positive Pressure gradient

Mass ratio of oxidizer to fuel

Truncated Ideal Contour
Inflection angle
Temperature exponent
Expansion ratio
Contraction ratio
Gas constant
Equivalence ratio
Auto ignition delay

\section{Introduction}

D

URING the last decades, the development of the Ariane 5 launcher family directed the concentration of Europe's launcher propulsion research activities and the development of numerical models for rocket engines to the propellant combination LOX/H2. This improved Europe's knowledge in the utilization of this particular cryogenic propellant combination and is the reason why limited knowledge and experience in the handling of hydrocarbon fuel combinations exists in western Europe.

The growing interest in reusable space transportation systems brings the use of methane as fuel of the next generation rocket engines more into focus. Compared to kerosene, methane has several advantages for the application as rocket engine fuel. Using the same engine cycle, the specific impulse of a LOX/CH4 motor is about $10 \mathrm{~s}$ higher than for a LOX/Kerosene engine. ${ }^{1}$ As a cooling fluid, methane can take off the same heat flux as kerosene while using only half of the cooling fluid mass flow rate. ${ }^{2}$ In addition less soot deposition is observed for methane oxidation compared to kerosene. ${ }^{3}$ Methane is easier to

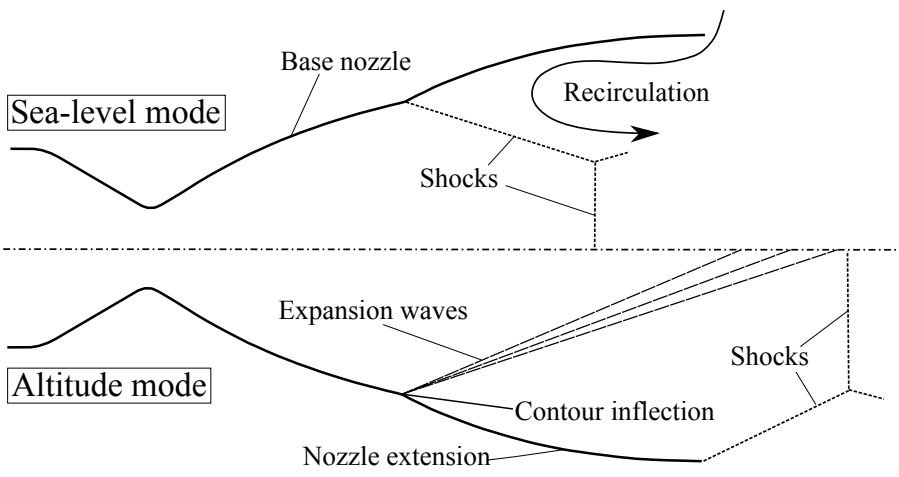

Figure 1. Principle of a dual bell nozzle. store in comparison to hydrogen because of its higher molecular weight and is therefore a better choice for in-space application with long durations. The higher density of methane compared to hydrogen allows for smaller fuel tanks (less structure mass) and yields less pumped volume over time for the turbo pumps. Therefore, the European industry and research institutes like the German Aerospace Center (DLR) have to increase efforts on developing and validating 
numerical models, for the behavior prediction of rocket engine parts utilizing the propellant combination $\mathrm{LOX} / \mathrm{CH} 4 .^{4}$

The present study concentrates on the development of a numerical model for the prediction and investigation of the transition behavior of a dual bell nozzle ${ }^{5-10}$ under LOX/CH4 hot flow conditions. The dual bell nozzle is an altitude compensating nozzle concept. It combines the advantage of a nozzle with small expansion ratio under sea-level conditions and a nozzle with large area ratio under high altitude conditions. The main stage engine of modern parallel staged launchers like the European heavy launcher Ariane 5 is ignited prior to the booster stage for safety reasons. This means the main stage engine has to operate over a wide range of altitude from sea-level up to almost vacuum conditions. Due to potential flow separation under high ambient pressure conditions, the expansion ratio of conventional nozzles is limited. The consequence of the expansion ratio limitation is a reduced performance under high altitude conditions. The dual bell nozzle consists of a base nozzle and a nozzle extension linked by an abrupt change in wall angle. This contour inflection forces the flow to a controlled and symmetrical separation under sea-level conditions. During ascend of the launcher the ambient pressure decreases. After reaching a given nozzle pressure ratio (total combustion chamber pressure over ambient pressure), the flow separation position moves abruptly to the exit area of the dual bell nozzle extension and a higher expansion ratio is reached for a wide range of the launcher trajectory. This increase of engine performance yields a potential payload gain. ${ }^{11}$ The principle of the dual bell nozzle concept is illustrated in figure 1. Sea-level mode (top) and altitude mode (bottom) are both well known stable operation conditions and are of lesser interest in scientific research. The main focus is on the transition from one mode to the other.

\section{Basic Numerical Verification}

\section{A. The DLR-TAU-Code}

The numerical study was performed with the second order finite-volume DLR-Navier-Stokes flow solver TAU, ${ }^{12}$ which has been validated for a wide range of steady and unsteady sub-, trans- and hypersonic flows. ${ }^{13}$ For the present investigation, TAU was applied to solve the Reynolds-averaged Navier-Stokes equations on two-dimensional and axisymmetric hybrid structured/unstructured grids. Turbulence modeling was conducted using the Spalart-Allmaras turbulence model ${ }^{14}$ which yielded good results for the prediction of the separation position in over-expanded nozzle flows ${ }^{15}$ and of the dual bell nozzle flow transition behavior. ${ }^{16-18}$ The AUSMDV ${ }^{19}$ upwind scheme was applied for discretization of the inviscid flux terms. A MUSCL-type gradient reconstruction was used to achieve second order spatial accuracy. Viscous terms were computed applying a second order central discretization. Time integration was performed by an implicit backward Euler method with LU-SGS scheme. Time-accurate solutions were obtained using a Jameson-type dual time-stepping scheme ${ }^{20}$ with second order temporal discretization, applying a physical time step of $1 \cdot 10^{-6} \mathrm{~s}$. An Arrhenius approach was applied for the modeling of the combustion processes in the reactive flow in chemical non-equilibrium. The flow is considered as a reacting mixture of thermally perfect gases. The thermodynamic properties are given by a look-up table and a dedicated transport equation is solved for each individual chemical species. The Arrhenius law ${ }^{21}$ in the form:

$$
k=A_{r} T^{\beta} e^{\frac{-E_{\mathrm{ac}}}{\mathcal{R} T}}
$$

yields the forward reaction rates. Where $k$ is the reaction rate of the dedicated chemical reaction. The backward rates are obtained from the equilibrium constant. A detailed overview of the thermo-chemical modelling for reacting flows in chemical non-equilibrium used in the DLR-TAU-code is given by Karl. ${ }^{22}$

\section{B. Auto Ignition Delay}

For the intended hot flow simulations of the dual bell nozzle flow field, a thermo-chemistry model for methane oxidation in chemical non-equilibrium had to be implemented in DLR's flow solver TAU. A 66-step methane reaction mechanism ${ }^{23}$ for low-pressure methane combustion with NOx formation submodel containing 23 species was applied, because of the main interest in the supersonic low-pressure part of the thrust nozzle.

Auto ignition delay simulations were conducted and compared with experimental data from Petersen et al., ${ }^{24}$ to evaluate the validity of the methane reaction mechanism implementation. Therefore, transient numerical simulations of the self ignition process in a volume filled with a mixture of methane, oxygen and 
Table 1. Composition of the gas mixture used for the determination of the auto ignition delay.

\begin{tabular}{lccc} 
Mixture & $X_{\mathrm{CH} 4}$ & $X_{\mathrm{O} 2}$ & $X_{\mathrm{N} 2}$ \\
\hline $\mathrm{CH} 4 / \mathrm{O} 2 / \mathrm{N} 2$ & 0.0525 & 0.2098 & 0.7377
\end{tabular}

nitrogen at different pressures and temperatures were carried out. Table 1 lists the mole fractions of the different mixture components. The gas mixture had a fuel-lean equivalence ratio of $\Phi=0.5$. A mixture set of seven cases at different pressures and temperatures was investigated. Table 2 summarizes the start conditions of the seven conducted transient auto ignition delay simulations and lists the experimentally obtained auto ignition delay from Petersen.

Table 2. Experimental conditions and auto ignition delay time data given by Petersen et al. ${ }^{24}$.

\begin{tabular}{cccc} 
Case & $\mathrm{T}[\mathrm{K}]$ & $\mathrm{p}[\mathrm{atm}]$ & $\tau_{\text {ign }}[\mu \mathrm{s}]$ \\
\hline 1 & 2001 & 0.54 & 56 \\
2 & 1854 & 0.55 & 106 \\
3 & 1673 & 0.73 & 284 \\
4 & 1611 & 0.79 & 430 \\
5 & 1526 & 0.74 & 978 \\
6 & 1451 & 0.80 & 1951 \\
7 & 1431 & 0.92 & 2369
\end{tabular}

Figure 2 illustrates the temperature raise over time in the examined volume, for the auto ignition cases 1 to 7 . It can be observed that a higher initial temperature results in a faster increase of the internal volume temperature which leads to a shorter auto ignition delay duration. Starting at a lower temperature the gas mixture takes much longer to auto ignite.

The temperature data of the different configurations were used for the evaluation of the dedicated auto ignition delays. The moment of auto ignition was defined through a given increase in temperature between two time steps. The definition for the determination of the auto ignition delay was kept constant for all configurations. Figure 3 depicts the comparison of the numerically obtained auto ignition delays and the

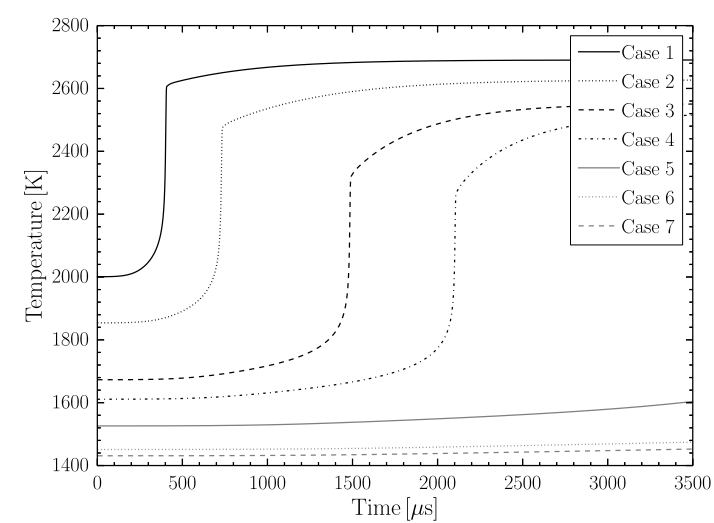

Figure 2. Increase of the inner volume temperature during auto ignition of different $\mathrm{CH} 4 / \mathrm{O} 2 / \mathrm{N} 2$ mixtures.

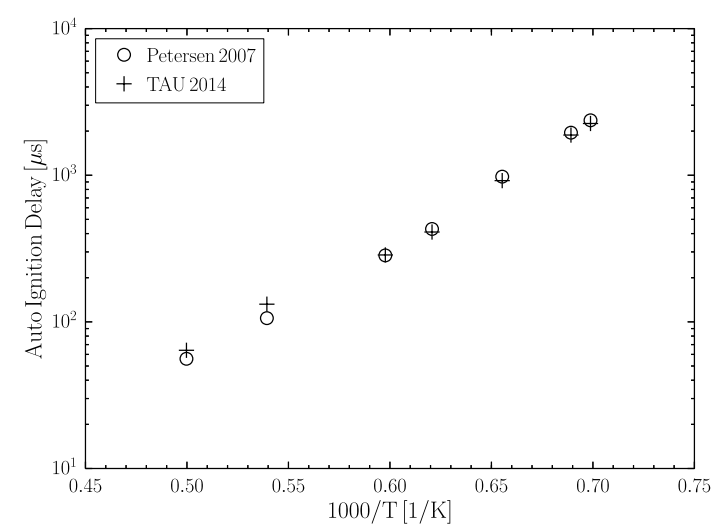

Figure 3. Numerically obtained auto ignition delays for Case 1 to 7 compared with experimental data of Petersen.

experimental data from Petersen et al. ${ }^{24}$ A very good agreement between the numerical and experimental data is shown. Thus, the implementation of the methane reaction mechanism for low-pressure application in DLR's flow solver TAU is considered valid and can be utilized for more extensive problems. 


\section{Reactive Nozzle Flow in Chemical Non-Equilibrium}

The implemented and validated chemical reaction mechanism for low-pressure methane combustion was applied on a generic nozzle configuration. Therefore, a 2D axisymmetric RANS simulation of the generic nozzle flow was conducted. The generic nozzle had a throat radius of $100 \mathrm{~mm}$ and a total length of $L_{\mathrm{t}} / R_{\mathrm{th}}=$ 9.0. The expansion ratio was 14.0 and the contraction ratio 4.0. Only the inner nozzle flow was simulated,

Table 3. Geometrical parameters of the generic nozzle

\begin{tabular}{lcc} 
Name & Symbol & Value \\
\hline Throat radius & $R_{\mathrm{th}}$ & $10 \mathrm{~mm}$ \\
Contraction ratio & $\epsilon_{c}=A_{\mathrm{cc}} / A_{\mathrm{th}}$ & 4.0 \\
Expansion ratio & $\epsilon=A_{\mathrm{e}} / A_{\mathrm{th}}$ & 14.0 \\
Total nozzle length & $L_{\mathrm{t}} / R_{\mathrm{th}}$ & 9.0
\end{tabular}

without considering the flow field around the nozzle. The geometrical parameters of the generic nozzle are listed in table 3.

The flow was considered to be 2Daxisymmetric. A combustion chamber mixture ratio (ROF) of 3.2 was chosen, which corresponds to real engine operation condition. ${ }^{1}$ At the nozzle inlet a reservoir-pressure boundary condition was applied, specifying total pressure and density. The corresponding flow conditions were computed with isentropic expansion from the total conditions towards the local flow velocity. The residence time of the combustion gases in the combustion chamber was assumed long enough to reach chemical equilibrium. Thus, the flow entered the nozzle in

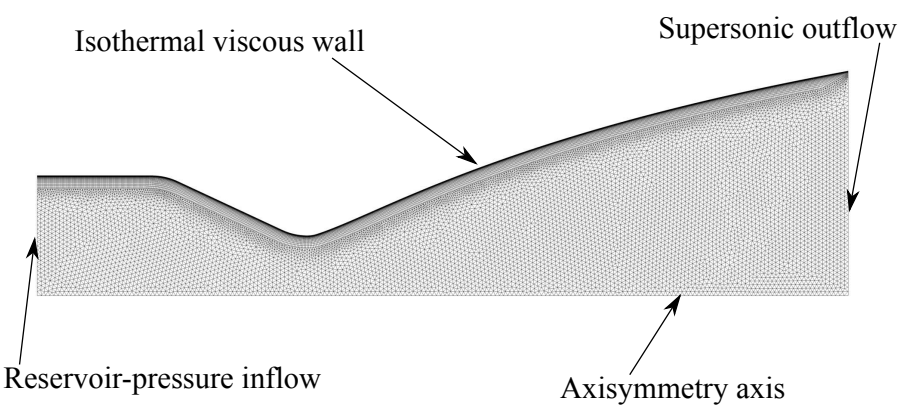

Figure 4. Boundary conditions of the generic nozzle flow simulations. chemical equilibrium state. For the nozzle wall a full turbulent, viscous, non catalytic and isothermal boundary condition was applied. The temperature of the nozzle wall was specified to $400 \mathrm{~K}$. At the nozzle exit area a supersonic outflow boundary condition was defined. The influence of the modeled turbulence on the detailed chemistry was neglected. Figure 4 illustrates the numerical grid of the generic nozzle flow simulation and the dedicated boundary conditions. A hybrid grid was applied with a structured part along the nozzle wall to resolve the boundary layer and an

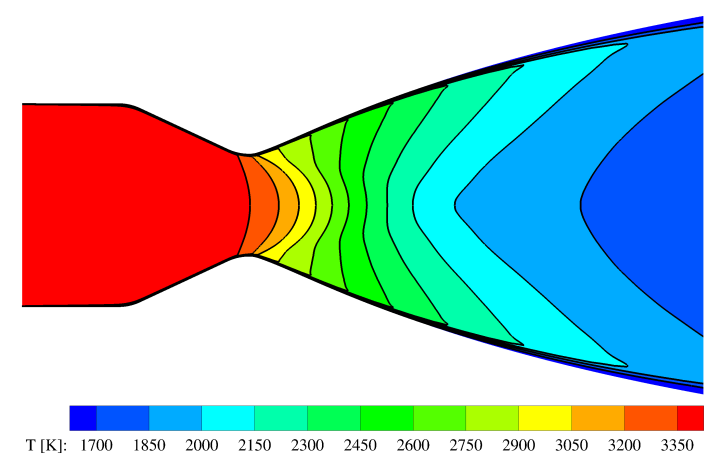

Figure 5. Temperature distribution of the generic nozzle configuration flow field.

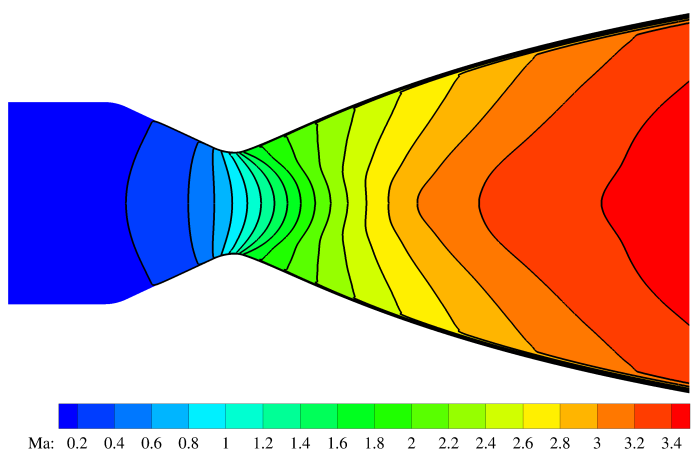

Figure 6. Mach number distribution of the the generic nozzle configuration flow field.

unstructured part discretizing the rest of the flow field. Due to the expansion of the combustion gases, the temperature decreases in flow direction. Thus, the dissociated molecules in the combustion chamber recombine. The temperature distribution of the generic nozzle flow field is depicted by figure 5. A combustion 
temperature higher than $3350 \mathrm{~K}$ can be observed for the chemical equilibrium state. Due to the expansion of the combustion gases, the temperature decreases to less than $1700 \mathrm{~K}$. Figure 6 illustrates the dedicated Mach number distribution of the generic nozzle flow simulation. A Mach number higher than 3.4 is reached at the exit area of the nozzle. The mass fraction distribution along the generic nozzle center line of all the 20 species occurring in the combustion gas is illustrated in figure 7. Hereinafter, the non-equilibrium simulation

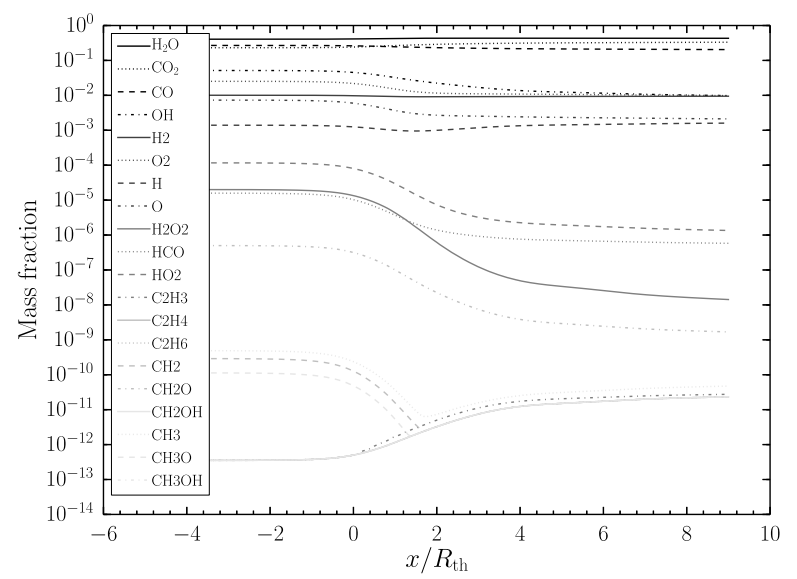

Figure 7. Mass fraction distribution along the nozzle center line for the generic nozzle flow in chemical non-equilibrium.

result, using the full reaction mechanism of Slavinskaya et al. ${ }^{23}$ is considered as the reference solution for the authors. All following simulations are compared to this baseline simulation.

\section{Frozen Nozzle Flow}

An approximation for the LOX/CH4 nozzle flow simulations is desirable, because of the very high computational costs for the application of the 66-step reaction mechanism. If the chemical time scales are much higher than the aerodynamic time scales, no reactions will occur inside the nozzle. The hot gas would leave the nozzle before the reactions start. This condition is called frozen nozzle flow. If real rocket engines would

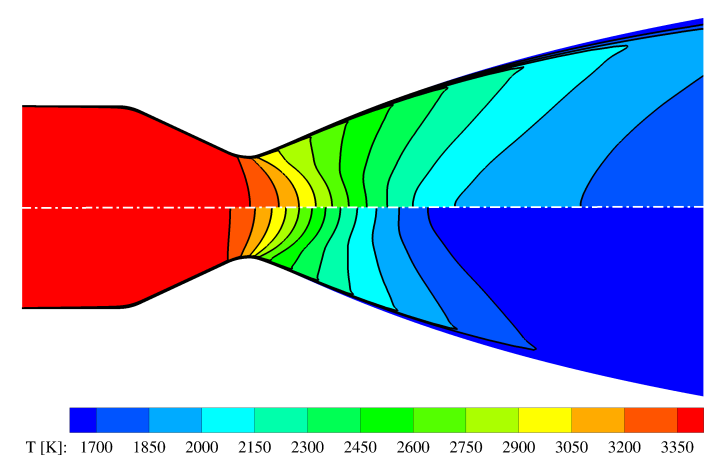

Figure 8. Comparison of the temperature distribution between the generic nozzle flow in chemical non-equilibrium (top) and the frozen (bottom) generic nozzle flow.

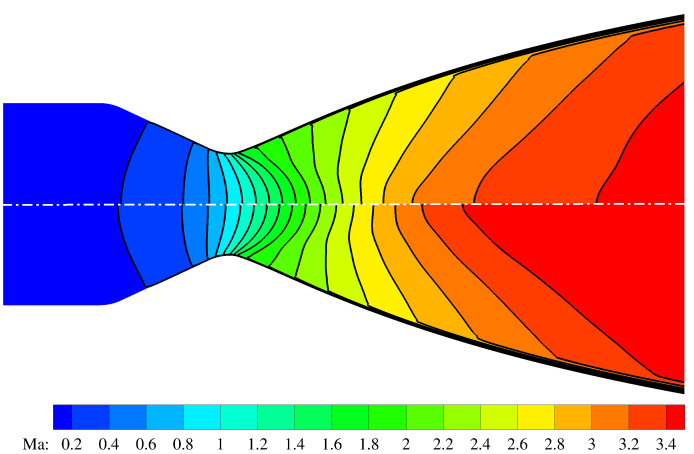

Figure 9. Comparison of the Mach number distribution between the generic nozzle flow in chemical non-equilibrium (top) and the frozen (bottom) generic nozzle flow (bottom).

show this behavior, a significant reduction of the computational costs would be feasible.

RANS simulations of the generic nozzle flow were conducted, applying a frozen chemical model. All geometry values and boundary conditions were the same as the ones used for the chemical non-equilibrium simulations. The results of the frozen nozzle flow were compared to the chemical non-equilibrium results to investigate the impact of a finite-rate chemistry on a LOX/CH4 hot gas nozzle flow. 
Figure 8 illustrates the comparison of the temperature distributions between the non-equilibrium and the frozen nozzle flow simulation results. Due to less recombination of the dissociated molecules, the temperature in the flow field of the frozen condition is lower than the temperature of the non-equilibrium flow field. This has a direct impact on the Mach number distribution as illustrated in figure 9. It can be observed, that the Mach numbers along the generic nozzle of the frozen case are much higher than of the non-equilibrium case. This difference in Mach number would have a strong impact on the flow separation position, ${ }^{25}$ in simulations of a highly over-expanded and separated nozzle flow. Thus, the approximation of a frozen nozzle flow seems not to be valid in the case of a LOX/CH4 combustion and expansion. In addition the not valid assumption

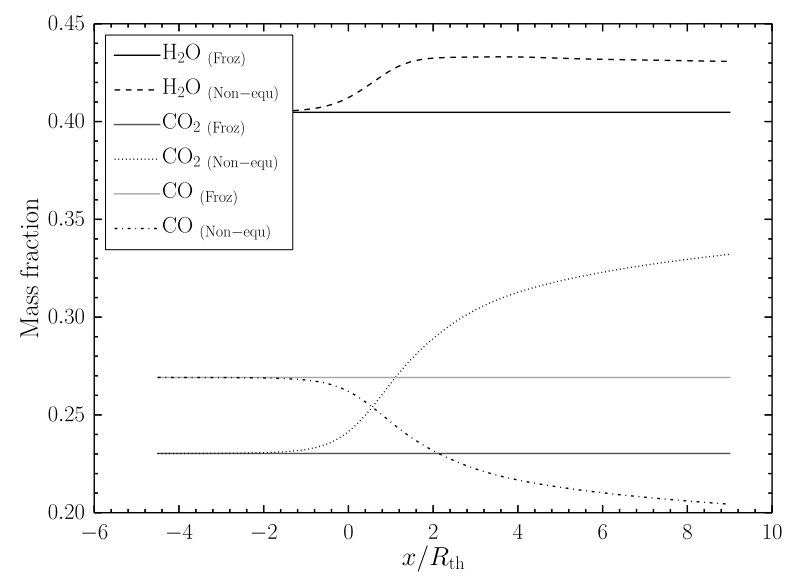

Figure 10. Comparison of the mass fraction distribution along the generic nozzle center line between the frozen nozzle flow and the nozzle flow in chemical non-equilibrium.

can be observed in figure 10. Here, for both cases the mass fraction development of the three major species in the combustion gas water, carbon dioxide and carbon monoxide is illustrated. For the frozen conditions no reaction takes place and the mass fractions along the generic nozzle are constant. Downstream of the nozzle throat at $x / R_{t h}=0$ the deviation from the non-equilibrium solution increases. The largest deviation can be observed for carbon dioxide at the nozzle exit area. The frozen nozzle flow assumption could also lead to an underestimation of the heat flux inside the nozzle wall, compared to a finite-rate chemistry. ${ }^{26}$

\section{E. Reactive Nozzle Flow in Chemical Equilibrium}

The other extrema for an approximation of the LOX/CH4 nozzle flow is an assumption of chemical equilibrium everywhere in the flow field. This means that the chemical time scales are much smaller than the aerodynamic time scales. Thus, the hot gas spends enough time in each control volume, which is used to discretize the nozzle flow, to reach locally chemical equilibrium. A valid chemical equilibrium assumption would lead to a significant reduction of computational cost, because of the possible tabulation of the chemical composition in dependency to the temperature and the density before the simulation and an interpolation between the tabulated values during the simulation.

A RANS simulation of the generic nozzle flow using the chemical equilibrium approach was conducted and the results were compared with the non-equilibrium simulation. All boundary conditions were the same as for the chemical non-equilibrium and the frozen flow simulations. The impact of an chemical equilibrium approach compared to the non-equilibrium approach is illustrated in the figures 11-13.

Figure 11 depicts the temperature distribution for the two different chemical reaction models. A higher temperature level in the flow field of the chemical equilibrium approach can be observed. Reaching the chemical equilibrium state emits more heat, because of the ongoing reactions in the flow field after reaching the non-equilibrium condition of the baseline simulation. The dedicated Mach number distribution of the generic equilibrium flow field is illustrated in figure 12. It can be observed, that the Mach numbers of the chemical equilibrium simulations are significantly lower than in the chemical non-equilibrium flow field. The chemical equilibrium assumption is not applicable for a highly overexpanded and separated nozzle flow simulation under LOX/CH4 hot flow conditions, because of the direct impact of the Mach number on the flow separation behavior. ${ }^{25}$ 


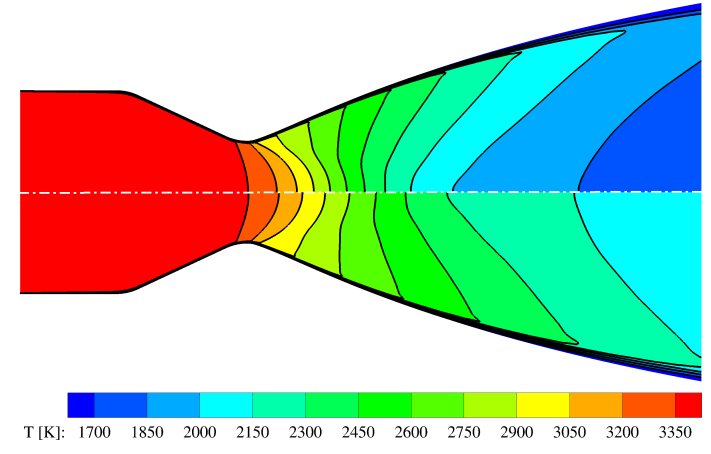

Figure 11. Comparison of the temperature distribution between the generic nozzle flow in chemical non-equilibrium (top) and in chemical equilibrium (bottom).

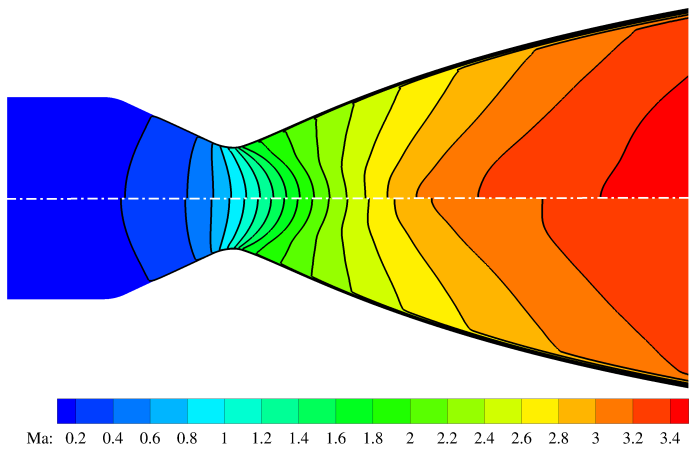

Figure 12. Comparison of the Mach number distribution between the generic nozzle flow in chemical non-equilibrium (top) and and in chemical equilibrium (bottom).

Figure 13 illustrates the comparison of the major species mass fractions along the nozzle center line, between the chemical equilibrium and non-equilibrium flow simulations. Here, a better agreement with

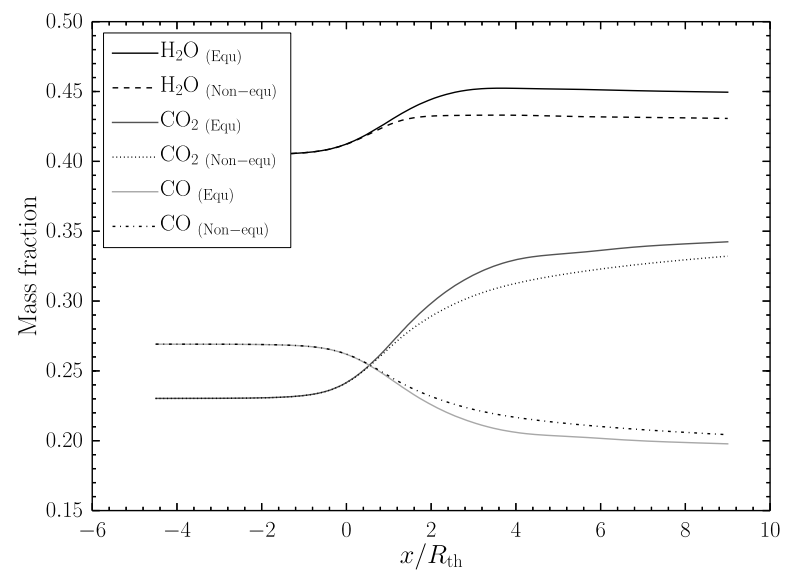

Figure 13. Comparison of the mass fraction distribution along the generic nozzle center line between the nozzle flow in chemical equilibrium and in chemical non-equilibrium.

the non-equilibrium results can be observed than it was obtained by applying the frozen nozzle flow approach. In addition to the mentioned disadvantages, the chemical equilibrium assumption could lead to an overestimation of the heat flux inside the nozzle wall, compared to a finite-rate chemistry. ${ }^{26}$

\section{F. Reduced Chemical Reaction Mechanism for Nozzle Flow Application}

The reaction mechanism of Slavinskaya et al. was reduced by applying an engineering approach, because the frozen and the chemical equilibrium nozzle flow assumptions were not reliable for a later application on overexpanded dual-bell nozzles. In order to reduce computational costs, all species with an mass fraction less than $1 \cdot 10^{-3}$ (cf. figure 7 ) were neglected. Thus, only the reactions composed of the left over species were taken into account.

This yielded a not closed 7-step reaction mechanism, for the expansion of reactive LOX/CH4 combustion gas in a hypersonic nozzle containing 10 species. The chemical reactions and the dedicated values for the Arrhenius law (cf. equation 1) are listed in table 4. Third body efficiencies are considered due to different Arrhenius factors. The later conducted simulations applying the reduced chemical reaction mechanism yielded a computational cost reduction of $93 \%$ compared to the chemical baseline model.

The reduced reaction mechanism was applied to the generic nozzle flow simulations, using the same 
Table 4. Equations and Arrhenius parameters used for the reduced chemical reaction mechanism

\begin{tabular}{ccccc} 
Number & Reaction & $A_{r}\left[\frac{m^{3}}{m o l \cdot s}\right.$ or $\left.\frac{m^{6}}{m l^{2} \cdot s}\right]$ & $\beta[-]$ & $E_{\mathrm{ac}}[\mathrm{K}]$ \\
\hline 1 & $\mathrm{O} 2+\mathrm{CO} \rightleftharpoons \mathrm{CO} 2+\mathrm{O}$ & $1.26 \cdot 10^{7}$ & 0 & 23682.94 \\
$2 \mathrm{a}$ & $\mathrm{CO}+\mathrm{O}+\mathrm{O} 2 \rightleftharpoons \mathrm{CO} 2+\mathrm{O} 2$ & 616 & 0 & 1510.7 \\
$2 \mathrm{~b}$ & $\mathrm{CO}+\mathrm{O}+\mathrm{CH} 4 \rightleftharpoons \mathrm{CO} 2+\mathrm{CH} 4$ & 4620 & 0 & 1510.7 \\
$2 \mathrm{c}$ & $2 \mathrm{CO}+\mathrm{O} \rightleftharpoons \mathrm{CO} 2+\mathrm{CO}$ & 1155 & 0 & 1510.7 \\
$2 \mathrm{~d}$ & $\mathrm{CO}+\mathrm{O}+\mathrm{H} \rightleftharpoons \mathrm{CO} 2+\mathrm{H}$ & 1540 & 0 & 1510.7 \\
$2 \mathrm{e}$ & $\mathrm{CO}+2 \mathrm{O} \rightleftharpoons \mathrm{CO} 2+\mathrm{O}$ & 1540 & 0 & 1510.7 \\
$2 \mathrm{f}$ & $\mathrm{CO}+\mathrm{O}+\mathrm{N} 2 \rightleftharpoons \mathrm{CO} 2+\mathrm{N} 2$ & 1540 & 0 & 1510.7 \\
$2 \mathrm{~g}$ & $\mathrm{CO}+\mathrm{O}+\mathrm{CO} 2 \rightleftharpoons \mathrm{CO} 2+\mathrm{CO} 2$ & 2310 & 0 & 1510.7 \\
$2 \mathrm{~h}$ & $\mathrm{CO}+\mathrm{O}+\mathrm{OH} \rightleftharpoons \mathrm{CO} 2+\mathrm{OH}$ & 1540 & 0 & 1510.7 \\
$2 \mathrm{i}$ & $\mathrm{CO}+\mathrm{O}+\mathrm{H} 2 \rightleftharpoons \mathrm{CO} 2+\mathrm{H} 2$ & 1540 & 0 & 1510.7 \\
$2 \mathrm{j}$ & $\mathrm{CO}+\mathrm{O}+\mathrm{H} 2 \mathrm{O} \rightleftharpoons \mathrm{CO} 2+\mathrm{H} 2 \mathrm{O}$ & 10010 & 0 & 1510.7 \\
3 & $\mathrm{OH}+\mathrm{H} 2 \rightleftharpoons \mathrm{H} 2 \mathrm{O}+\mathrm{H}$ & 216 & 1.52 & 1740 \\
4 & $\mathrm{H} 2+\mathrm{O} \rightleftharpoons \mathrm{OH}+\mathrm{H}$ & $5.86 \cdot 10^{8}$ & 0 & 4578.4 \\
5 & $\mathrm{H}+\mathrm{O} 2 \rightleftharpoons \mathrm{OH}+\mathrm{O}$ & $2.06 \cdot 10^{8}$ & -0.097 & 7560 \\
6 & $\mathrm{H} 2 \mathrm{O}+\mathrm{O} \rightleftharpoons 2 \mathrm{OH}$ & 4.139 & 2.1187 & 7574.57 \\
7 & $\mathrm{CO}+\mathrm{OH} \rightleftharpoons \mathrm{CO} 2+\mathrm{H}$ & 0.31 & 1.83 & -682
\end{tabular}

boundary conditions as before. The obtained results were compared to the chemical non-equilibrium simulation results. Figure 14 illustrates the comparison of the temperature distributions. A good agreement of the temperature field can be observed. Figure 15 depicts the comparison of the Mach number distribution. Compared to the results of the frozen and the chemical equilibrium approach, the Mach number distribution of the 7-step simulation agrees well with the 66-step simulation results. The 7-step approach seems

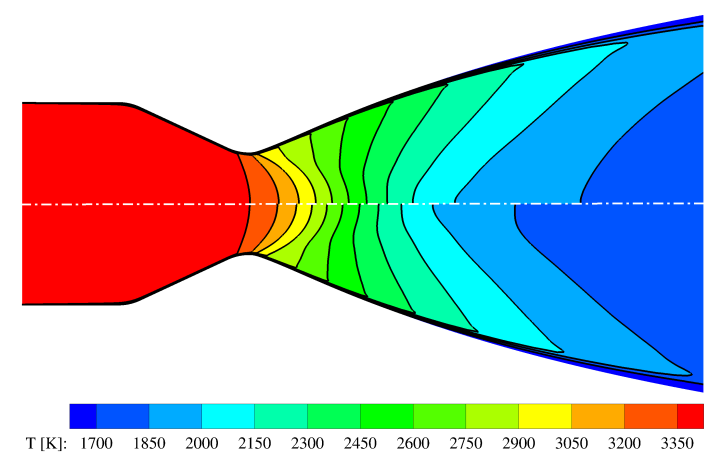

Figure 14. Comparison of the temperature distribution between the 66-step (top) and the 7-step reaction mechanism (bottom).

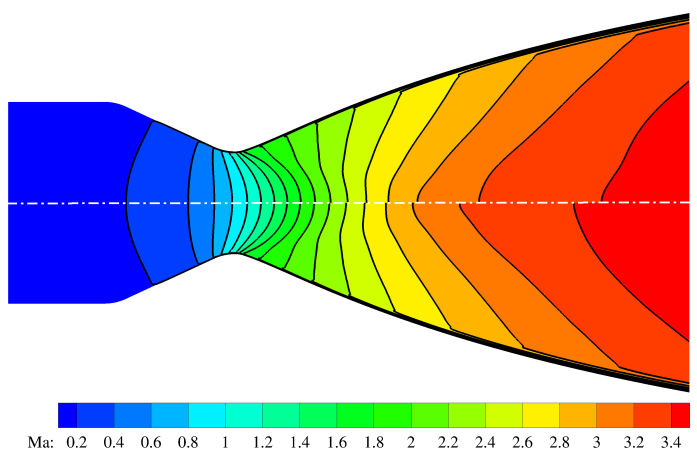

Figure 15. Comparison of the Mach number distribution between the 66-step (top) and the 7-step reaction mechanism (bottom).

to be promising for the prediction of the flow separation position in highly overexpanded thrust nozzles under LOX/CH4 hot flow conditions, because of the good agreement in Mach number distribution. ${ }^{25}$ In downstream direction with increasing flow expansion the deviation from the 66-step simulation increases slightly.

Figure 16 illustrates the mass fraction development along the nozzle center line for the three major species water, carbon dioxide and carbon monoxide. These three species together account more than $90 \%$ of the total combustion gas mass. The agreement of the 66-step and 7-step RANS simulations is satisfying along the entire generic nozzle.

Figure 17 depicts the mass fraction development along the nozzle wall for the three major species. The combustion gas composition near the wall would be important, if a reliable estimation of the heat flux 
inside the wall is requested. Upstream of the nozzle throat a large deviation between the 66-step and 7-step simulations can be observed. Downstream of the nozzle throat the agreement of the two different approaches increases. Thus, for the estimation of the combustion gas composition at the wall of the combustion chamber

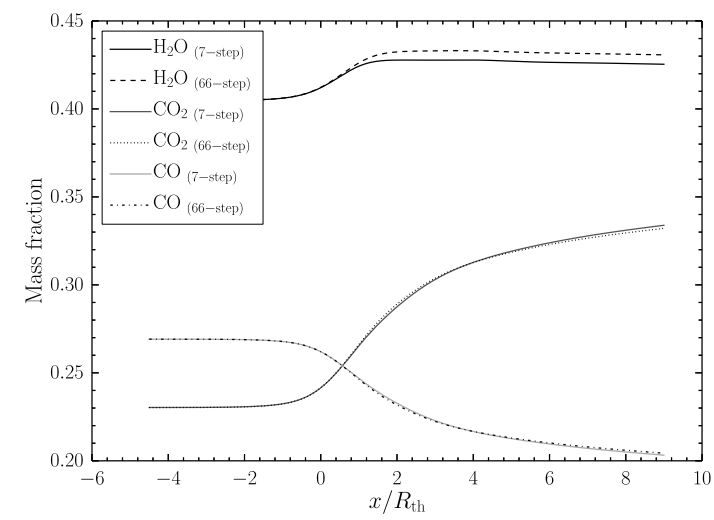

Figure 16. Comparison of the mass fraction distribution along the nozzle center line between the 66-step and the 7 -step reaction mechanism.

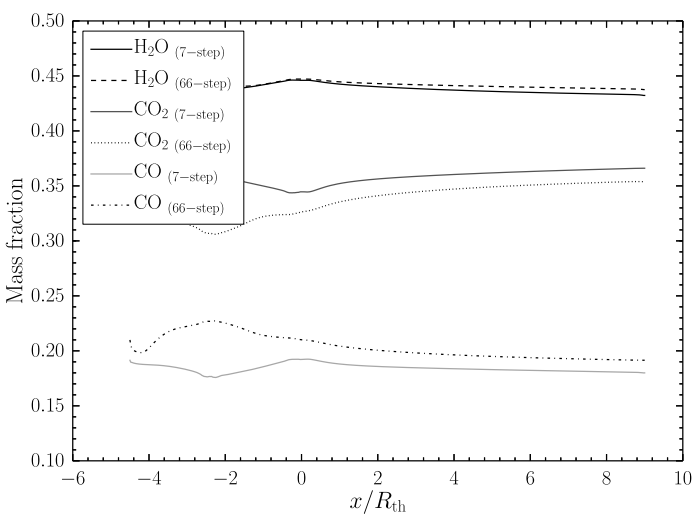

Figure 17. Comparison of the mass fraction distribution along the nozzle wall between the 66-step and the 7 -step reaction mechanism.

or the convergent part of the thrust nozzle the 7-step approach is not a reliable choice. But for a estimation downstream of the nozzle throat the 7-step reaction mechanism yields good agreement with the baseline model. The developed 7-step chemistry model seems to be a reliable simulation tool, due to the main interrest in boundary layer separation in the divergent part of the thrust nozzle downstream of the nozzle throat. Further validation is conducted in the following sections.

\section{Experimental Setup}

\section{A. Dual-Bell Nozzle Test Specimen}

Validation data, for the following numerical simulations of the dual-bell nozzle transition behavior under LOX/CH4 hot flow conditions, were obtained by a hot firing test campaign at DLR's test facility P6.1 in Lampoldshausen. The main focus during the test campaign was on the investigation of the influence of the combustion chamber mixture ratio on the transition behavior of a dual-bell nozzle.

Therefore, a dual-bell nozzle model was designed using a DLR in-house code based on the method of characteristics (MOC). ${ }^{27}$ The contour of the base nozzle was designed as a truncated ideal contour (TIC)

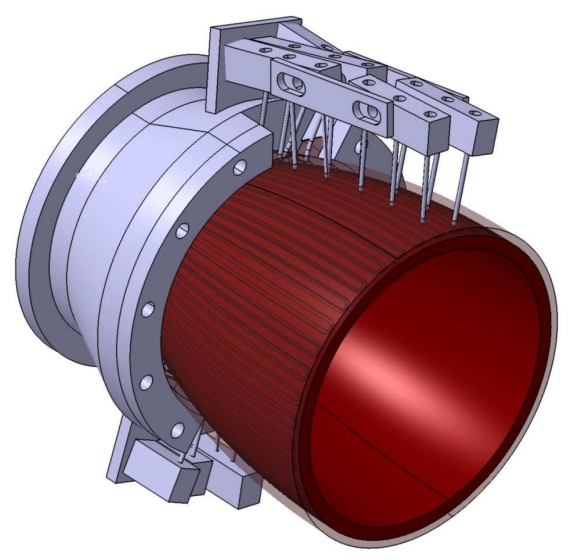

Figure 18. Construction plot of the tested dual-bell nozzle model.

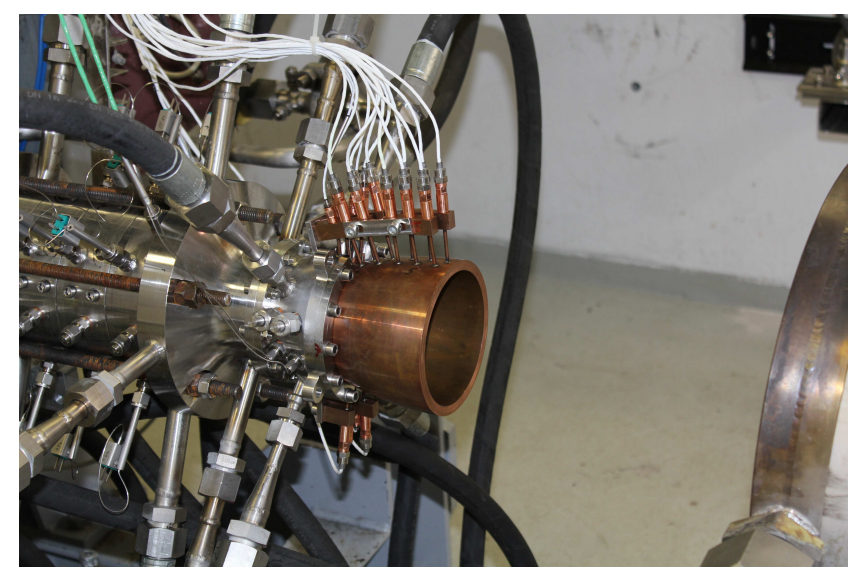

Figure 19. Dual-bell nozzle model mounted at test facility P6.1 in Lampoldshausen. 
with a design Mach number $\mathrm{Ma}_{\mathrm{d}}$ of 3.5. This ensured a undisturbed flow field at the nozzle exit without internal shocks interacting with the free shock separation shock pattern. The design mixture ratio for the nozzle was 3.2 .

The dual-bell nozzle was designed with a positive wall pressure gradient (PP) along the nozzle extension. A dual-bell nozzle configuration with TIC base nozzle and PP extension was proved to ensure a fast transition

Table 5. Geometrical parameter of the investigated dual bell nozzle model

\begin{tabular}{lcc} 
Name & Symbol & Value \\
\hline Throat radius & $R_{\mathrm{th}}$ & $10 \mathrm{~mm}$ \\
Area ratio base nozzle & $\epsilon_{\mathrm{b}}=A_{\mathrm{b}} / A_{\mathrm{th}}$ & 13.5 \\
Area ratio extension & $\epsilon_{\mathrm{e}}=A_{\mathrm{e}} / A_{\mathrm{th}}$ & 28.9 \\
Base nozzle length & $L_{\mathrm{b}} / R_{\mathrm{th}}$ & 8.0 \\
Extension length & $L_{\mathrm{e}} / R_{\mathrm{th}}$ & 9.6 \\
Total nozzle length & $L_{\mathrm{t}} / R_{\mathrm{th}}$ & 17.6 \\
Inflection angle & $\alpha_{\mathrm{i}}$ & $12^{\circ}$
\end{tabular}

from sea-level to altitude mode for cold flow conditions. ${ }^{18}$ The nozzle had a total length of $176 \mathrm{~mm}$ and a throat radius of $10 \mathrm{~mm}$. The base nozzle and the nozzle extension were linked by a contour inflection angle of $12^{\circ}$. Expansion ratios of the base nozzle and the nozzle extension with all important geometrical parameters of the nozzle model are listed in table 5.

The dual bell nozzle model was made of copper alloy due to the high thermal conductivity and therefore good cooling properties. Figure 18 illustrates a sketch of the dual-bell nozzle model. For the regenerative water cooling, the nozzle model was equipped with forty cooling channels. These cooling channels were milled in the nozzle model and closed by galvanization. The water was distributed inside the cooling channels by a manifold at $\epsilon=5$, directed to the nozzle lip and redirected to the manifold. This complex configuration was chosen, in order to realize realistic flow conditions at the nozzle exit area without flow disturbance by a manifold. Figure 19 depicts the dual-bell nozzle model mounted at DLR's test facility P6.1 in Lampoldshausen.

\section{B. Test Conditions and Instrumentation at Test Facility P6.1}

The tests were conducted at DLR's hot flow test facility P6.1 in Lampoldshausen. The test site offers testing of sub-scale combustion chambers and nozzles, using the cryogenic propellant combinations oxygen/hydrogen or oxygen/methane. For the present study methane was chosen as fuel. The hot gas for the nozzle investigation was generated by a combustion chamber with a diameter of $50 \mathrm{~cm}$ and a injection head with 15 coaxial injector elements. Criterion for the length of the combustion chamber was to reach almost chemical equilibrium at the inlet of the dual bell nozzle. The maximum propellant mass flow rate was $1.5 \mathrm{~kg} / \mathrm{s}$. In order to reach an almost constant temperature of $400 \mathrm{~K}$ along the wall, the nozzle was over-cooled with a cooling water mass flow rate of approx. $3 \mathrm{~kg} / \mathrm{s}$. The test duration was limited to approx. $90 \mathrm{~s}$ by the amount of cooling water available.

Wall pressure data were obtained by the application of dynamic pressure transducers. Sixteen dynamic pressure transducers were placed along the dual-bell nozzle extension, to track the separation position during transition and retransition of the flow. The distance between the pressure ports was $8 \mathrm{~mm}$. In the vicinity of the contour inflection the resolution was increased by a pressure port interval of $2 \mathrm{~mm}$. The sampling frequency of the Kulites was $25 \mathrm{kHz}$. For the protection of the transducers, they were placed in copper blocks at a short distance from the nozzle model. The transducers were connected to the hot flow through thin pipes and $0.8 \mathrm{~mm}$ orifices at the end.

Figure 20 illustrates a typical test profile of the conducted investigations. During the tests the combustion chamber pressure was ramped up and down to reach different nozzle pressure ratios $\left(\mathrm{NPR}=p_{0} / p_{a}\right)$. The mixture ratio in the combustion chamber was kept as constant as possible during the tests. The blue line in figure 20 indicates the signal of a pressure transducer in the dual-bell nozzle extension. When a specific value of combustion chamber pressure is reached, transition to altitude mode takes place and the pressure in the extension decreases abruptly due to the attached hot gas flow. After a period of time in altitude mode 


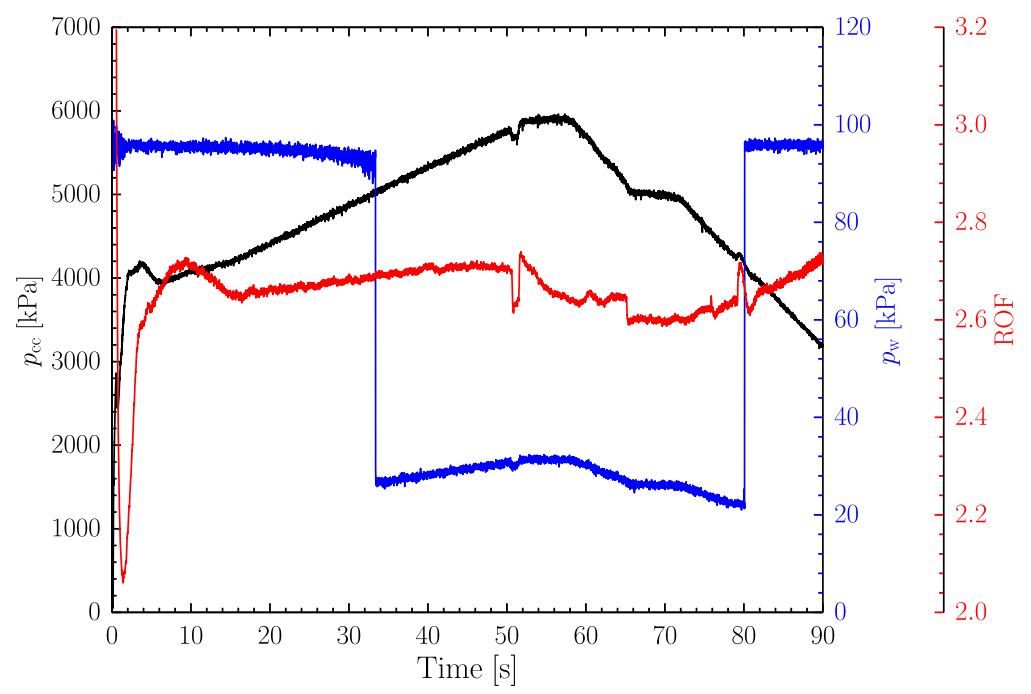

Figure 20. Example for a test profile of a LOX/CH4 hot flow experiment conducted at test facility P6.1.

the combustion chamber pressure is decreased again until the retransition NPR is reached. At this point the pressure in the nozzle extension increases again back to almost ambient pressure. The gap between transition and retransition NPR is called dual-bell hysteresis and is a well known effect from cold flow experiments. ${ }^{28}$

\section{Experimental Results}

In order to investigate the impact of the combustion chamber mixture ratio on the transition and retransition NPR, several test runs at different ROFs were conducted. The transition and retransition ROF had to be determined based on the experimental mass flow rate data of the liquid oxygen and the methane, because of the fluctuating ROF during the test. Figure 21 illustrates the transition and retransition NPRs as a function

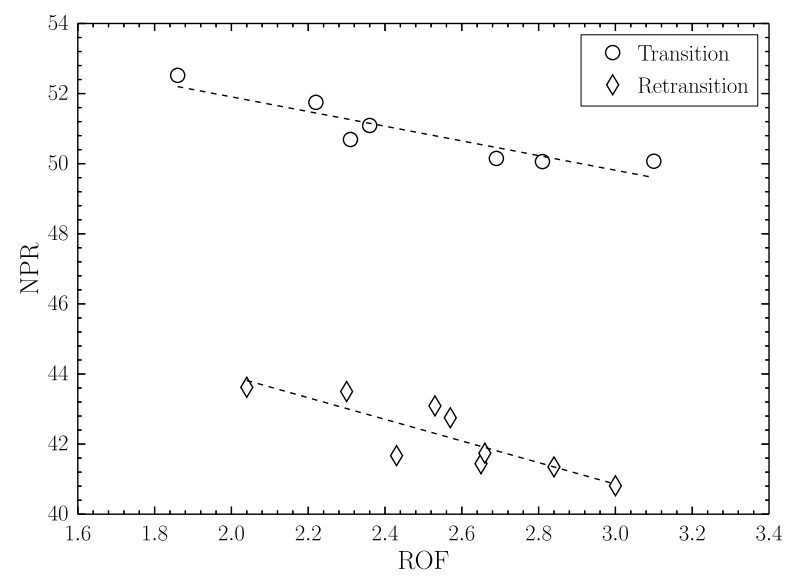

Figure 21. Transition and retransition NPR as a function of combustion chamber mixture ratio for all conducted test runs.

of ROF for all conducted test runs. A clear impact of the mixture ratio on the transition and retransition NPR can be observed. With decreasing ROF the transition and retransition NPRs increase and the hysteresis between them decreases. This dependency of the transition and retransition NPR and the mixture ratio could be used for an active control of the dual-bell nozzle during flight. Thus, for the transition to altitude mode the buffeting phase could be avoided and the dual-bell transition could be triggered at a specific altitude. 
Changing the mixture ratio would be easier than varying the combustion chamber pressure as proposed in former studies. A more detailed evaluation of the experimental results is given by Génin et al. ${ }^{29}$ The obtained experimental data are used in the following sections, for the validation of the numerical modelling of the dual-bell transition behavior under LOX/CH4 hot flow conditions.

\section{Numerical Investigation of the Dual-Bell Nozzle Flow}

\section{A. Numerical Setup}

RANS simulations of the dual-bell nozzle flow under LOX/CH4 hot flow conditions were conducted, in order to investigate the transition behavior and to validate the reduced chemical reaction mechanism. The simulations were carried out on 2D axisymmetric hybrid (structured/unstructured) grids. Figure 22 illustrates the numerical computation domain with the applied boundary conditions. The ambient conditions around the nozzle were modeled by applying a flux-based far-field boundary condition. ${ }^{30}$ In order to minimize the

$45 \mathrm{Lt}$

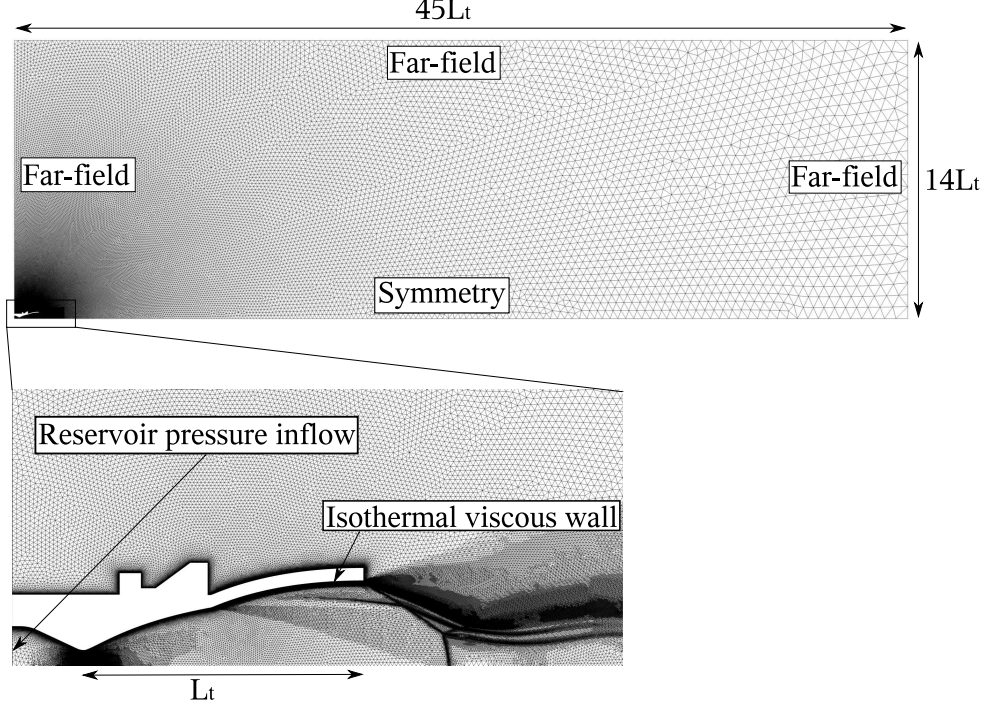

Figure 22. Numerical computation domain, boundary conditions and adapted nozzle grid of the dual-bell nozzle investigation.

influence of the far-field boundary conditions, the dimensions of the computational domain were $45 \cdot L_{\mathrm{t}}$ in the x-direction by $14 \cdot L_{\mathrm{t}}$ in the z-direction. For the nozzle inflow and the nozzle wall, the same boundary conditions were applied as the ones described for the generic nozzle flow simulations. Along the nozzle wall a turbulent boundary layer was assumed. Prismatic sublayers along the inner nozzle wall were used to resolve the viscous boundary layer. A dimensionless wall spacing of $y^{+}=\mathcal{O}(1)$ was applied, to ensure a sufficient resolution of the laminar sublayer. A detailed grid study was conducted to show the grid independence of the obtained results. Furthermore, a density gradient based indicator was used to control the fully automated grid adaptation in the vicinity of shocks and shear layers. The adapted grid is illustrated at the bottom of figure 22 .

\section{B. Reactive Dual-Bell Nozzle Flow in Chemical Non-Equilibrium}

Based on the authors cold flow expertise ${ }^{16}$ dual-bell nozzle flow RANS simulations were carried out to validate the introduced 7 -step reaction mechanism and to investigate the impact of the combustion chamber mixture ratio on the dual-bell transition behavior. Therefore, RANS simulations at different NPRs were conducted. The result of each simulation was used as initial condition for the next NPR step. At each NPR step grid adaptation was applied to increase the grid resolution in the vicinity of high density gradients (shocks/shear layers). After each adaptation step, full convergence was reached. The numerical grid was refined, until no more impact on the flow field was observed. For each NPR step the separation position of the dual-bell nozzle flow was determined. 
Figure 23 illustrates the comparison of the experimentally measured wall pressure distributions at NPR 40 and 58 and the dedicated wall pressure distributions obtained by the 66-step RANS simulations. Both determined at ROF 3.07. In case of the experiments the dual-bell nozzle is in clear sea-level mode at NPR 40. The flow separates at the contour inflection at $x / R_{\mathrm{th}}=8.0$ and the wall pressure in the extension increases to almost ambient conditions. Then the pressure remains almost constant until the exit plane of the nozzle.

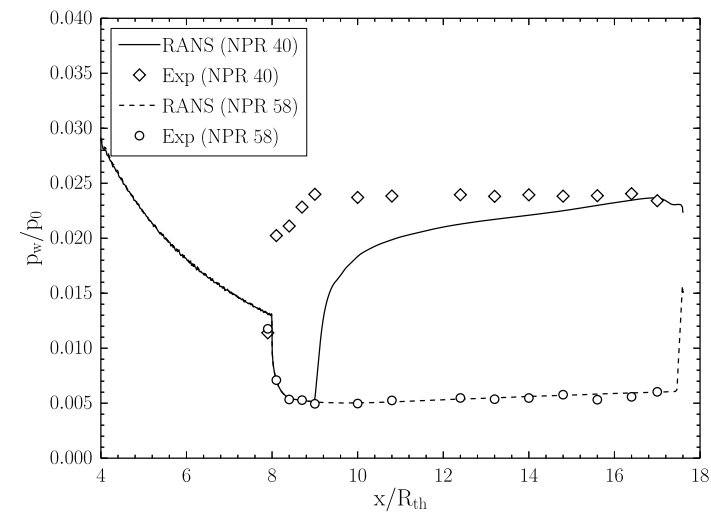

Figure 23. Wall pressure distribution of the dualbell nozzle in at NPR 40 and NPR 58 mode applying 66-step reaction mechanism.

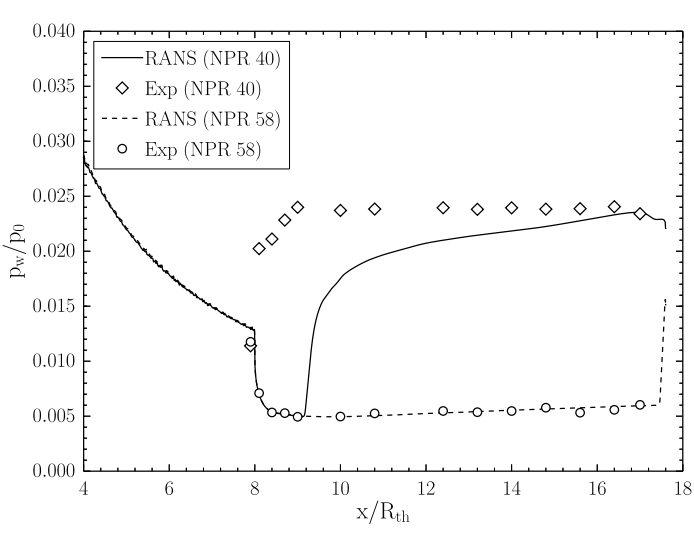

Figure 24. Wall pressure distribution of the dualbell nozzle in NPR 40 and NPR 58 mode applying 7-step reaction mechanism.

It can be observed, that for the simulation at NPR 40 the separation position is already located in the

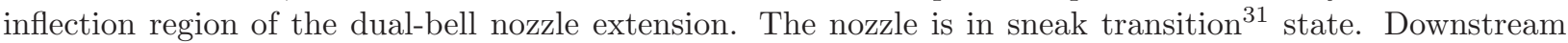
to the separation position the wall pressure increases, but the level of the experimental wall pressure is not reached. Thus, the wall pressure increases progressively up to the experimental value at the nozzle exit area. This behavior of the numerical wall pressure in the region of the recirculation flow of a dual-bell nozzle in

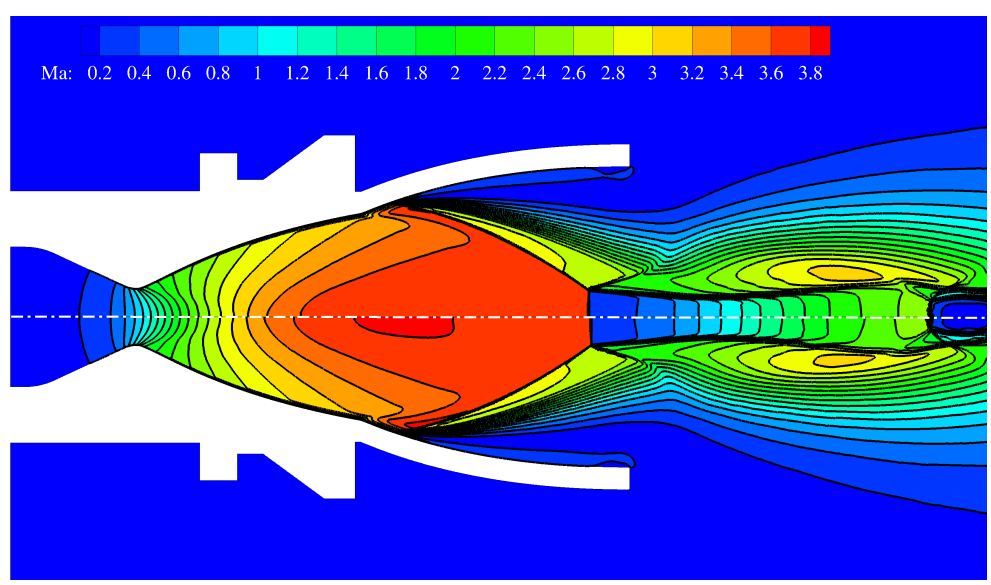

Figure 25. Comparison of the Mach number distribution at NPR 40 and ROF 3.07 between 66-step (top) and 7-step (bottom) chemistry.

sea-level mode is also observed in the case of cold flow simulations applying the Spalart-Allmaras turbulence model. ${ }^{16}$ The discrepancy is not a result of the applied chemistry model.

Figure 24 depicts the same plot for the 7-step reaction mechanism, which was introduced before. Almost no difference between 66-step and 7-step results can be observed. Only a slightly more downstream flow separation for the 7 -step reaction mechanism occurs.

Figure 25 illustrates the comparison of the Mach number distribution between the 66-step and 7-step simulations at ROF 3.07 for NPR 40. A clear sneak transition state can be observed for both chemical models. In the core flow the Mach number of the 7-step simulation is slightly higher than for the baseline model. In terms of estimating the Mach number and wall pressure distribution the 7-step reaction mechanism 
is a satisfying approach.

The dual-bell transition behavior for the 66-step and 7-step simulations is illustrated in figure 26. Here, the separation positions of the dual-bell nozzle flow is plotted as a function of NPR. Almost no difference between the two reaction mechanisms can be observed. Between NPR 40 and 46 the flow separation position moves slightly inside the dual-bell nozzle extension. Between NPR 46 and 49 transition takes place and the

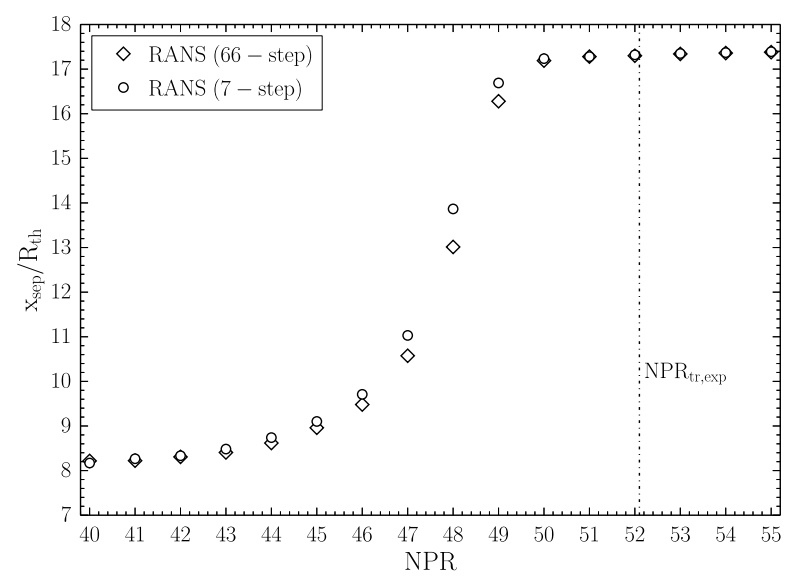

Figure 26. Dual-bell transition behavior at ROF 2.0 for the 66-step and 7-step reaction mechanism compared with the experimental value.

flow separation position moves downstream to the nozzle exit area. At NPR 50 the flow separation position reaches the end effect regime at approx. $95 \%$ of the dual-bell nozzle extension length. This value was defined as the numerical transition NPR. During the experiments transition occurred at approx. NPR 52 . This means a deviation between experimental and numerical value of approx. $4 \%$. The 7 -step methane reaction mechanism saved $93 \%$ of computational cost and yielded the same results for the dual-bell nozzle flow transition behavior prediction.

Figure 27 illustrates the transition NPR as a function of mixture ratio for the RANS simulations using the reduced chemical mechanism, the experiments and the prediction obtained from the design method based on MOC. For all three methods a clear impact of the ROF on the transition NPR can be observed. With decreasing ROF the transition NPR shifts to higher values. With increasing ROF the influence of ROF

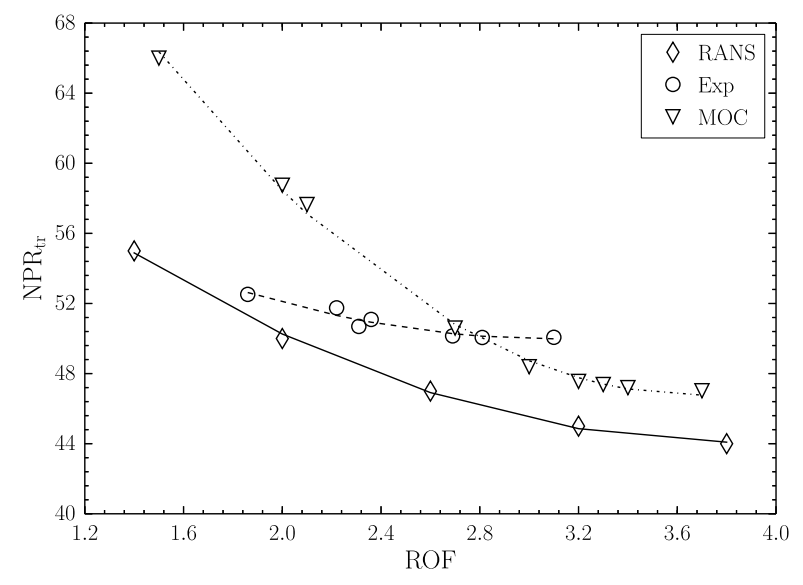

Figure 27. Impact of the combustion chamber mixture ratio on the dual-bell transition nozzle pressure ratio.

gets weaker and the curves approach asymptotically to a specific value. Compared to the experiments the MOC overestimates the impact of the ROF, especially at low ROFs. At ROF 2.0 the agreement of the RANS simulations with the experiments is satisfying. With increasing ROF the deviation between RANS 
simulation and experiment increases and reaches a maximum value of $14 \%$ at ROF 3.1 .

\section{Conclusions}

A numerical model was developed to investigate the dual-bell transition behavior under LOX/CH4 hot flow conditions. Therefore, the DLR-Navier-Stokes flow solver TAU was upgraded with a 66 -step chemical reaction mechanism for LOX/CH4 combustion under low pressure conditions. Auto ignition delay simulations were conducted to prove the validity of the implementation. Then the 66-step reaction mechanism was applied for RANS simulations of a generic nozzle flow. This baseline simulation was compared to chemical equilibrium simulations and to a frozen nozzle flow approach to study the impact of a finite rate chemistry on a reactive hypersonic nozzle flow under $\mathrm{LOX} / \mathrm{CH} 4$ hot flow conditions and to investigate a potential save in computational cost. The chemical baseline model was reduced to a basic 7-step configuration, because of the not satisfying results in terms of reducing the computational cost. This setup yielded good agreement with the original baseline model and was applied on a dual-bell nozzle flow. Validation data were obtained by a hot flow test campaign. Here, the influence of the combustion chamber mixture ratio on the dual-bell transition NPR was shown. With decreasing ROF the transition NPR is shifted to higher values. This behavior could be a potential control mechanism to take influence on the dual-bell transition altitude during the flight of a launcher with dual-bell nozzle engine. RANS simulations of the dual-bell nozzle flow were conducted, using the 66-step baseline- and the 7-step chemical mechanism. Almost no difference between the two approaches for the dual-bell transition was observed. The 7-step chemistry seems to be sufficient for the study of the flow expansion in supersonic nozzles and can save up to $93 \%$ of computational effort compared to the baseline model. The reduced chemical model was applied for RANS simulations of the dual-bell transition at different ROF. The impact of the ROF on the transition NPR was clearly reproduced by the numerical approach. A maximum transition NPR prediction deviation of $14 \%$ for a ROF of 3.1 was reached.

\section{Acknowledgments}

Financial support has been provided by the German Research Foundation (Deutsche Forschungsgemeinschaft) in the framework of the Sonderforschungsbereich Transregio 40. The authors would like to thank the members of the DLR internal collaboration ProTAU for supporting the numerical studies. Special thanks go to the P6.1 team Tony Brüssow, Alex Baskal, and Dmitry Suslov for the good collaboration at the test bench and Dietmar Maier and Christian Mader for their help in the manufacturing process of the test specimen.

\section{References}

\footnotetext{
${ }^{1}$ Burkhardt, H., Sippel, M., Herbertz, A., and Klevanski, J., "Kerosene vs Methane: A Propellant Tradeoff for Reusable Liquid Booster Stages," Journal of Spacecraft and Rockets, Vol. 41, No. 5, 2004, pp. 762-769, doi:10.2514/1.2672.

${ }^{2}$ Klepikov, I. A., Katorgin, B. I., and Chvanov, V. K., "The New Generation of Rocket Engines, Operating by Ecologically Safe Propellant "Liquid Oxygen and Liquefied Natural Gas (Methane)"," Acta Astronautica, Vol. 41, 1997, pp. 209-217, doi:10.1016/S0094-5765(98)00076-9.

${ }^{3}$ Götz, A., Mäding, C., Brummer, L., and Haeseler, D., "37th AIAA/ASME/SAE/ASEE Joint Propulsion Conference \& Exhibit," Application of Non-Toxic Propellants for Future Advanced Launcher Vehicles, AIAA Paper 2001-3546, Salt Lake City, USA, July 2001, doi:10.2514/6.2001-3546.

${ }^{4}$ Preclik, D., Hagemann, G., Knab, O., Mäding, C., Haeseler, D., Haidn, O., Woschnak, A., and DeRosa, M., "41st AIAA/ASME/SAE/ASEE Joint Propulsion Conference \& Exhibit," LOX/Hydrocarbon Preparatory Thrust Chamber Technology Activities in Germany, AIAA Paper 2005-4555, Tuscon, Arizona, USA, July 2005, doi:10.2514/6.2005-4555.

${ }^{5}$ Foster, C. R. and Cowles, F. B., "Experimental Study of Gas-Flow Separation in Overexpanded Exhaust Nozzles for Rocket Motors," Technical report, Jet Propulsion Laboratory, 1949.

${ }^{6}$ Horn, M. and Fisher, S., "Dual-Bell Altitude Compensating Nozzles," Tech. Rep. CR-194719, NASA, 1994.

${ }^{7}$ Hagemann, G., Immich, H., van Nguyen, T., and Dumnov, G. E., "Advanced Rocket Nozzles," Journal of Propulsion and Power, Vol. 14, No. 5, September 1998, pp. 620-634, doi:10.2514/2.5354.

${ }^{8}$ Frey, M. and Hagemann, G., "Critical Assessment of Dual-Bell Nozzles," Journal of Propulsion and Power, Vol. 15, No. 1, 1999, pp. 137-143, doi:10.2514/2.5402.

${ }^{9}$ Hagemann, G., Terhardt, M., Haeseler, D., and Frey, M., "Experimental and Analytical Design Verification of the Dual-Bell Concept," Journal of Propulsion and Power, Vol. 18, No. 1, January 2002, pp. 116-122, doi:10.2514/2.5905.

${ }^{10}$ Hagemann, G., Immich, H., and Dumnov, G., "Rocket Engine Nozzle Concepts," Progress in Astronautics and Aeronautics: Liquid Rocket Thrust Chambers, 2004, pp. 437-467, doi:10.2514/5.9781600866760.0437.0467.
} 
${ }^{11}$ Stark, R., Génin, C., Schneider, D., and Fromm, C. M., “Ariane 5 Performance Optimization Using Dual-Bell Nozzle Extension," Journal of Spacecraft and Rockets, 2016, doi:10.2514/1.A33363.

${ }^{12}$ Schwamborn, D., Gerhold, T., and Heinrich, R., "European Conference on Computational Fluid Dynamics," The DLR TAU-Code: Recent Applications in Research and Industry, Delft, Netherlands, 2006.

${ }^{13}$ Mack, A. and Hannemann, V., "32nd AIAA Fluid Dynamics Conference and Exhibit," Validation of the Unstructured DLR-TAU-Code for Hypersonic Flows, AIAA Paper 2002-3111, St. Louis, USA, June 2002, doi:10.2514/6.2002-3111.

${ }^{14}$ Spalart, P. R. and Allmaras, S. R., "A One-Equation Turbulence Model for Aerodynamic Flows," La Recherche Aérospatiale, Vol. 54, No. 1, 1994, pp. 5-21, doi:10.2514/6.1992-439.

${ }^{15}$ Stark, R. and Hagemann, G., "2nd European Conference for Aerospace Sciences (EUCASS)," Current Status of Numerical Flow Prediction for Separated Nozzle Flows, Brussels, Belgium, July 2007.

${ }^{16}$ Schneider, D. and Génin, C., "Numerical Investigation of Flow Transition Behavior in Cold Flow Dual-Bell Rocket Nozzles," Journal of Propulsion and Power, 2016, doi:10.2514/1.B36010.

${ }^{17}$ Génin, C., Stark, R., Karl, S., and Schneider, D., "48th AIAA/ASME/SAE/ASEE Joint Propulsion Conference \& Exhibit," Numerical Investigation of Dual Bell Nozzle Flow Field, AIAA Paper 2012-4164, Atlanta, USA, July 2012, doi:10.2514/6.2012-4164.

${ }^{18}$ Génin, C., Stark, R., and Schneider, D., "49th AIAA/ASME/SAE/ASEE Joint Propulsion Conference \& Exhibit," Transitional Behavior of Dual Bell Nozzles: Contour Optimization, AIAA Paper 2013-3841, San Jose, USA, July 2013, doi:10.2514/6.2013-3841.

${ }^{19}$ Wada, Y. and Liou, M.-S., "32nd Aerospace Sciences Meeting \& Exhibit," A Flux Splitting Scheme with High-Resolution and Robustness for Discontinuities, AIAA Paper 1994-0083, Reno, USA, January 1994, doi:10.2514/6.1994-83.

${ }^{20}$ Jameson, A., "10th Computational Fluid Dynamics Conference," Time Dependent Calculations Using Multigrid, with Applications to Unsteady Flows Past Airfoils and Wings, AIAA Paper 1991-1596, Honolulu, USA, June 1991, doi:10.2514/6.19911596.

${ }^{21}$ Arrhenius, S., "Über die Reaktionsgeschwindigkeit bei der Inversion von Rohrzucker durch Säuren," Z. Physik. Chem., Vol. 4, 1889, pp. 226-248. 2011.

${ }^{22}$ Karl, S., Numerical Investigation of a Generic Scramjet Configuration, Ph.D. thesis, Technischen Universität Dresden,

${ }^{23}$ Slavinskaya, N. A., Wiegand, M., Starcke, J. H., Riedel, U., Haidn, O., and Suslov, D., "Kinetic Mechanism for Low-Pressure Oxygen/Methane Ignition and Combustion," Progress in Propulsion Physics, Vol. 4, 2013, pp. 702-732, doi:10.1051/eucass/201304707.

${ }^{24}$ Petersen, E. L., Hall, J. M., Smith, S. D., de Vries, J., Amadio, A. R., and Crofton, M. W., "Ignition of Lean MethaneBased Fuel Blends at Gas Turbine Pressure," Journal of Engineering for Gas Turbines and Power, Vol. 129, 2007, pp. 937-944, doi:10.1115/1.2720543.

${ }^{25}$ Stark, R. and Wagner, B., "Experimental Study of Boundary Layer Separation in Truncated Ideal Contour Nozzles," Shock Waves, Vol. 19, No. 3, 2009, pp. 185-191, doi:10.1007/s00193-008-0174-6.

${ }^{26}$ Betti, B., Bianchi, D., Nasuti, F., and Martelli, E., "Chemical Reaction Effects on Heat Loads of CH4/O2 and H2/O2 Rockets," AIAA Journal, Vol. 54, No. 5, May 2016, pp. 1693-1703, doi:10.2514/1.J054606.

${ }^{27}$ Zucrow, M. J. and Hoffman, J. D., Gas Dynamics, Vol. 2: Multi-Dimensional Flow, John Wiley \& Sons, 99 th ed., 1977.

${ }^{28}$ Génin, C. and Stark, R., "Side Loads in Subscale Dual Bell Nozzle," Journal of Propulsion and Power, Vol. 27, No. 4, 2011, pp. 828-837, doi:10.2514/1.B34170.

${ }^{29}$ Génin, C., Schneider, D., Tomita, T., and Takahashi, H., "51st AIAA/SAE/ASEE Joint Propulsion Conference \& Exhibit," LOX/CH4 Hot Firing Dual Bell Nozzle Testing: Part I - Transitional Behavior-, AIAA Paper 2015-4155, Orlando, USA, July 2015, doi:10.2514/6.2015-4155.

${ }^{30}$ Whitfield, D. L. and Janus, J., "17th AIAA Fluid Dynamics, Plasma Dynamics and Lasers Conference," Three Dimensional Unsteady Euler Equations Solution Using Flux Vector Splitting, AIAA Paper 1984-1552, Snowmass, USA, June 1984, doi:10.2514/6.1984-1552.

${ }^{31}$ Génin, C. and Stark, R., "Experimental Study on Flow Transition in Dual Bell Nozzles," Journal of Propulsion and Power, Vol. 26, No. 3, May 2010, pp. 497-502, doi:10.2514/1.47282. 